\title{
Synthesis and electrocatalytic properties of $\mathrm{H}_{2} \mathrm{SO}_{4}$-induced (100) Pt nanoparticles prepared in water-in-oil microemulsion
}

\author{
Roberto A. Martínez-Rodríguez ${ }^{\mathrm{b}}$, Francisco J. Vidal-Iglesias ${ }^{\mathrm{a}}$, José Solla-Gullón ${ }^{\mathrm{a}}$, Carlos R. Cabrera ${ }^{\mathrm{b}}$, \\ and Juan M. Feliu*a
}

The increasing number of applications for shape-controlled metal nanoparticles leads to the need of easy, cheap and scalable methodologies. In this communication we report, the synthesis of (100) preferentially oriented platinum (Pt) nanoparticles with $9 \mathrm{~nm}$ particle size using a water-in-oil microemulsion method. The specific surface structure of the nanoparticles is induced by the presence of $\mathrm{H}_{2} \mathrm{SO}_{4}$ in the water phase of the microemulsion. Interestingly, the results here reported will show how increasing amounts of $\mathrm{H}_{2} \mathrm{SO}_{4}$ lead to the formation of $\mathrm{Pt}$ nanoparticles containing a higher amount of (100) sites on their surface. This preferential surface orientation has been confirmed electrochemically by using the so-called hydrogen adsorption/desorption process. In addition, TEM measurements have confirmed the presence of cubic-like Pt nanoparticles. Finally, the electrocatalytic properties of the Pt nanoparticles have been evaluated towards ammonia and CO electro-oxidations as (100) structure sensitive reactions.

Several methodologies for shape control of metal nanoparticles have been developed in the past decade with the main objective of controlling the specific arrangements of the atoms at their surface, that is, their surface structure. ${ }^{[1-4]}$ In this way, as widely demonstrated with metal single crystals as model electrodes, the catalytic properties of the metal nanostructures can be tuned and optimised for a particular reaction. Among others, and due to its unique catalytic properties, Pt nanoparticles have been the focus of numerous studies from which their remarkable surface structure sensitivity has been illustrated and discussed for several reactions of interest. ${ }^{[1,5]}$

On the other hand, from a more applied point of view, it would be desirable to have a simple, fast and economically viable methodology for the preparation of such shapecontrolled metal nanoparticles to be then scalable for large scale applications. However, most of the developed synthetic routes do not fulfil with these requirements and consequently, the scalability still remains a challenge. In this regard, in a very

[a] Dr. F.J. Vidal-Iglesias, Dr. J. Solla-Gullón, Prof. J.M. Feliu Institute of Electrochemistry University of Alicante

Ap. 99, 03080 Alicante, Spain

E-mail: juan.feliu@ua.es

[b] Mr. R.A. Martínez-Rodríguez, Prof C.R. Cabrera

NASA-URC Center for Advanced Nanoscale Materials (CANM),

Department of Chemistry

University of Puerto Rico

Río Piedras Campus, P.O. Box 23346, San Juan 00931-3346,

Puerto Rico recent publication, we have extended the use of water-in-oil microemulsions, traditionally employed for the preparation of metal nanoparticles with controlled atomic composition and size, for the preparation of shape-controlled Pt nanoparticles. In particular, we have reported that the addition of determined amounts of $\mathrm{HCl}$ in the water phase of the microemulsion led to the formation of $\mathrm{Pt}$ nanoparticles with a bell-shaped preferential (100) surface structure with a maximum of the (100) character at about $25 \%$ of $\mathrm{HCl}^{[6]}$ This approach opens new possibilities in terms of scalability because the handling of the water-in-oil microemulsions is easy, fast, economic and frequently performed at room temperature. In this communication, we will show that $\mathrm{H}_{2} \mathrm{SO}_{4}$ can be also used as effective (100) surface modifier during the preparation of $\mathrm{Pt}$ nanoparticles in microemulsion (see experimental section for details). The resulting $\mathrm{Pt}$ nanoparticles will be electrochemically characterized and their electrocatalytic properties evaluated towards carbon monoxide and ammonia electro-oxidation as (100) structure sensitive reactions.

Figure 1 shows the positive-going sweep voltammetric profiles for the nanoparticles prepared in the absence and presence of increasing amounts of $\mathrm{H}_{2} \mathrm{SO}_{4}(6.25 \%, 12.5 \%$ and $25 \%$ ) in $0.5 \mathrm{H}_{2} \mathrm{SO}_{4}$. These voltammetric profiles show the hydrogen and anion adsorption/desorption region, which is well established to reveal the actual nanoparticles' surface orientation at an atomic level. ${ }^{[7]}$ Very briefly, in a typical voltammogram, there are four main peaks located at $0.12,0.27$, 0.37 and $0.53 \mathrm{~V}$ vs RHE, which are related to the presence of (110) sites, (100) steps and terrace borders, (100) terraces or wide domains and (111) terraces, respectively. As it is clearly observed, when increasing the amount of $\mathrm{H}_{2} \mathrm{SO}_{4}$, the features assigned to the $(100)$ surface sites, both steps $(0.27 \mathrm{~V})$ and terraces $(0.37 \mathrm{~V})$, increase. On the contrary, the contribution related to the presence of (110) sites on the surface of the Pt nanoparticles diminishes thus counterbalancing the (100) contributions. This counterbalance between the (110) and (100) sites with the addition of $\mathrm{H}_{2} \mathrm{SO}_{4}$ can be easily followed by analysing the current density ratio of the signal at 0.12 and $0.27 \mathrm{~V}$, respectively, as a function of the $\%$ of $\mathrm{H}_{2} \mathrm{SO}_{4}$. The evolution of both contributions leads to the conclusion that the higher the amount of $\mathrm{H}_{2} \mathrm{SO}_{4}$, the higher the amount of (100) sites is. Unfortunately, the maximum amount of $\mathrm{H}_{2} \mathrm{SO}_{4}$ used had to be limited to $25 \%$ because of instability problems of the water-in-oil microemulsion for higher concentrations. Finally, a similar trend, i.e. decrease for increasing amounts of $\mathrm{H}_{2} \mathrm{SO}_{4}$, is also observed for the (111)-related peak, although this signal is less visible due to the low (111) character of these Pt nanoparticles. 


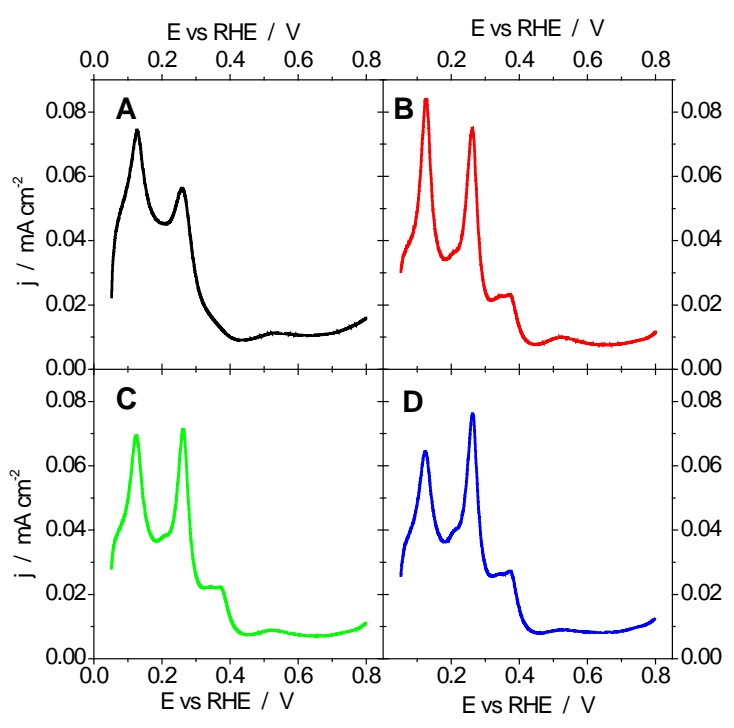

Figure 1. Voltammetric profiles for Pt nanoparticles prepared by water-in-oil microemulsion in the absence $(\mathrm{A})$ and presence of different amounts of $\mathrm{H}_{2} \mathrm{SO}_{4}\left(6.25 \%\right.$ (B), $12.5 \%$ (C) and $25 \%$ (D)). Test solution: $0.5 \mathrm{M} \mathrm{H}_{2} \mathrm{SO}_{4}$. Scan rate: $50 \mathrm{mVs}^{-1}$.

The voltammetric profiles reported here as a consequence of the presence of $\mathrm{H}_{2} \mathrm{SO}_{4}$ in the synthesis step are qualitatively similar to those obtained with $\mathrm{Pt}$ nanoparticles prepared in similar water-in-oil microemulsions but in the presence of $\mathrm{HCl}^{[6]}$ and with $\mathrm{Pt}$ nanoparticles prepared with different capping materials (sodium polyacrylate $(\mathrm{NaPa}){ }^{[8-10]}$ tetradecyltrimethylammonium bromide (TTAB) ${ }^{[11-13]}$ poly(vinylpyrrolidone) $(\mathrm{PVP})^{[14,15]}$ or oleic acid/oleylamine $\left.{ }^{[15]}\right)$ by means of various colloidal routes, in all of which cubic $\mathrm{Pt}$ nanoparticles were synthesised. In this regard, it is important to recall that, by simple analogy with the unit stereographic triangle of a fcc metal, a stereographic triangle with shaped fcc metal nanoparticles can be made in which the three apexes represent the coordinates of polyhedral nanocrystals bounded by basal facets (a cube, octahedron and rhombic dodecahedron enclosed by (100), (111) and (110) faces, respectively). ${ }^{[16-18]}$ Thus, a preferential (100) surface structure is the expected orientation from cubic Pt nanoparticles. Figure 2 shows representative TEM images of the nanoparticles prepared in the presence of different amounts of $\mathrm{H}_{2} \mathrm{SO}_{4}$. These TEM images were obtained by placing a drop of a diluted water suspension of the clean nanoparticles onto a Formvar-covered copper grid to avoid a serious damage of the carbon film by the $\mathrm{H}_{2} \mathrm{SO}_{4}$. However, this resulted in an important agglomeration of the samples. In any case, as shown in figure 2, nanoparticles tend to have a cubic-like shape, especially those prepared with the highest $\mathrm{H}_{2} \mathrm{SO}_{4}$ percentage (Figure $2 \mathrm{C}$ and $2 \mathrm{D}$ ). The particle size is quite similar for the three different amounts of $\mathrm{H}_{2} \mathrm{SO}_{4}(9.2 \pm 1.8,8.4$ \pm 1.8 and $9.0 \pm 1.7 \mathrm{~nm}$ for the $6.25,12.5$ and $25 \% \mathrm{H}_{2} \mathrm{SO}_{4}$, respectively). Interestingly, this particle size is smaller than those prepared in a similar microemulsion but in the presence of $\mathrm{HCl}$ where the particle size of the $\mathrm{Pt}$ nanoparticles with the highest amount of (100) sites was found to be about $13 \mathrm{~nm}^{\left[{ }^{[6]}\right.}$ This fact is very relevant from an applied point of view where the electrocatalytic activity is frequently expressed in terms of mass activity ( $\left.\mathrm{mA} \mathrm{mg}_{\mathrm{Pt}}\right)$. Thus, in a cubic Pt nanoparticle model, a $4 \mathrm{~nm}$ particle size decrease represents a $66 \%$ decrease in Pt mass which remarkably reduces the cost of the process. The Pt nanoparticles prepared in microemulsion in the absence of $\mathrm{H}_{2} \mathrm{SO}_{4}$ have been widely studied in some of our previous contributions and are characterized by a particle size of about $5 \mathrm{~nm}$ and a polyoriented surface structure ${ }^{[7,19]}$ as

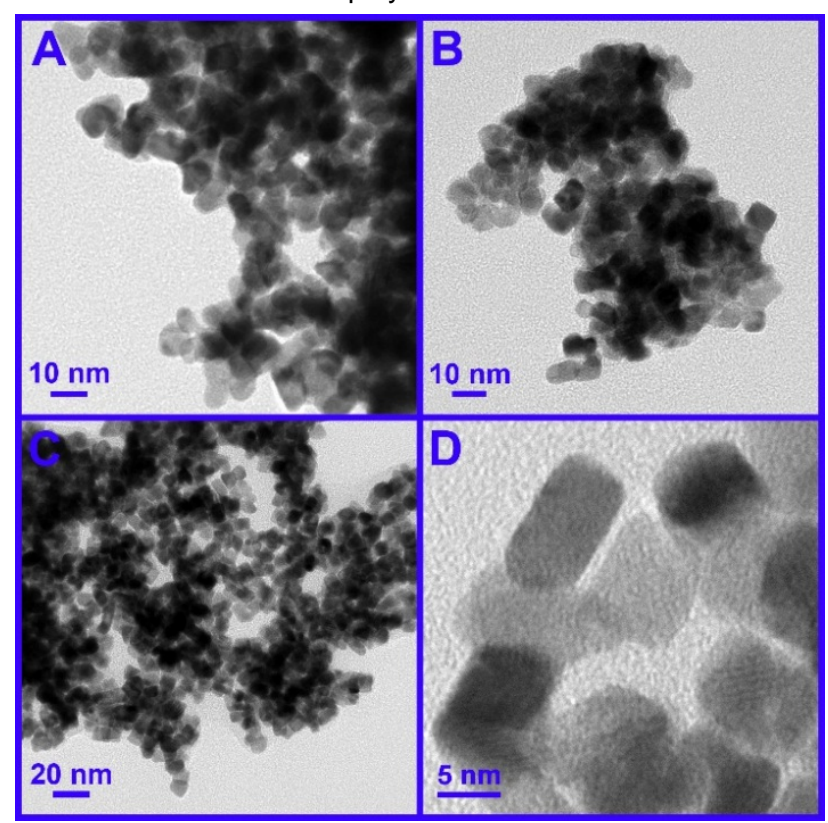

illustrated in figure $1 \mathrm{~A}$.

Figure 2. TEM image of platinum nanoparticles prepared by water-in-oil microemulsion in the presence of $6.25(\mathrm{~A}), 12.5$ (B) and $25 \%$ (C and D) $\mathrm{H}_{2} \mathrm{SO}_{4}$ in the aqueous phase.

Furthermore, to quantitatively estimate of the amount of (100) sites at the surface of the different Pt nanoparticles, the voltammetric profiles reported in figure 1 were subjected to a deconvolution process following a similar approach to that reported in previous contributions. ${ }^{[6,7]}$ The results obtained are shown in figure 3 (solid black squares). This analysis allows us to determine the total fraction of (100) surface sites, that is, both step and terrace contributions, to be properly estimated. Thus, as expected from the voltammetric responses, the total amount of (100) surface sites clearly increases and reaches a maximum value close to a $50 \%$ of the surface. However, from a fundamental point of view, it is of great importance to discriminate between (100) surface steps and terraces. Previous knowledge from Pt stepped surfaces evidenced that the electrochemical reactivity on steps and terraces can be markedly different. ${ }^{[20-23]}$ In previous contributions, we reported that the adsorption-desorption of Ge of Pt surfaces, both model and nanoparticulated electrodes, can be used to determine the amount of (100) terrace domains with a width $\geq 4 \mathrm{Pt}$ atoms (each $\mathrm{Ge}$ atom requires four platinum atoms to be adsorbed). ${ }^{[7}$,

${ }^{24,25]}$ Figure 3 (open red circles) shows the percentage of (100) surface domains obtained for the Pt nanoparticles prepared with different amounts of $\mathrm{H}_{2} \mathrm{SO}_{4}$. A simple inspection of the results obtained with the different approaches allows us estimating the (100) terraces to total (100) sites ratio on each Pt sample which ranges from a $50 \%$ to a maximum value of 
$65 \%$ for those Pt nanoparticles prepared in the presence of a $25 \%$ of $\mathrm{H}_{2} \mathrm{SO}_{4}$.

Finally, the electrocatalytic properties of the $\mathrm{Pt}$ nanoparticles were evaluated using two different (100) structure sensitive electrochemical reactions: ammonia electrooxidation on alkaline solution and $\mathrm{CO}$ stripping in acidic solution. Ammonia electro-oxidation is well-known to be extremely sensitive to the $\mathrm{Pt}$ surface structure, taking place almost exclusively on (100) sites and in particular on (100) twodimensional domains. ${ }^{[26]}$ This surface structure sensitivity has been illustrated not only on model Pt single crystal surfaces, both with stepped and basal orientations, but also in an important number of (100) oriented Pt nanostructures prepared by different methodologies. ${ }^{[6,8,27-30]}$ In all cases, the use of (100) oriented Pt nanoparticles resulted in enhanced electrocatalytic activities towards ammonia oxidation in comparison with polyoriented Pt nanoparticles.

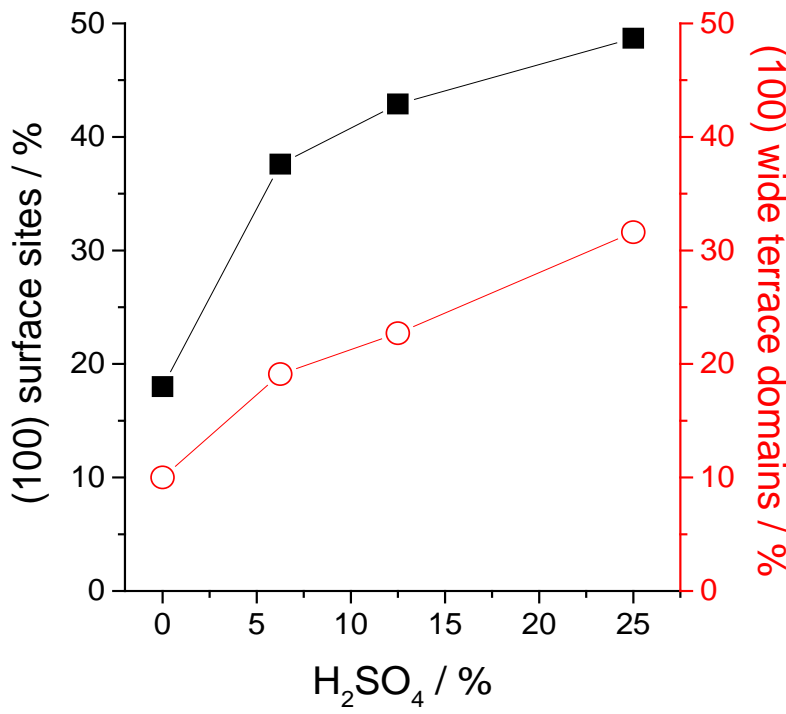

Figure 3. Amount of (100) sites measured by hydrogen adsorption/desorption deconvolution (solid black squares) and by $\mathrm{Ge}$ irreversible adsorption (open red circles) for different $\mathrm{H}_{2} \mathrm{SO}_{4} \%$ in the microemulsion.

Figure 4A shows the electrocatalytic activity toward ammonia oxidation of the nanoparticles prepared in the absence and presence of $6.25,12.5$ and $25 \% \mathrm{H}_{2} \mathrm{SO}_{4}$ in the water phase of the microemulsion. In full agreement with the results shown in figures 1 and 3 , those $\mathrm{Pt}$ nanoparticles containing a higher fraction of (100) surface sites display the best catalytic activity. This maximum activity is more than 3times higher than that obtained with the polyoriented $\mathrm{Pt}$ nanoparticles. Interestingly, as evidenced in figures $4 B$ and $4 C$, the ammonia oxidation activity (peak current density) is in excellent correlation with the amount of (100) terraces estimated from $\mathrm{Ge}$ analysis while this correlation is not so good if the total amount of (100) surface sites is estimated from the deconvolution analysis, in which all (100) surface sites are taken into account. This experimental feature again points out the extremely sensitivity of the ammonia oxidation reaction to the surface domains with a (100) symmetry.
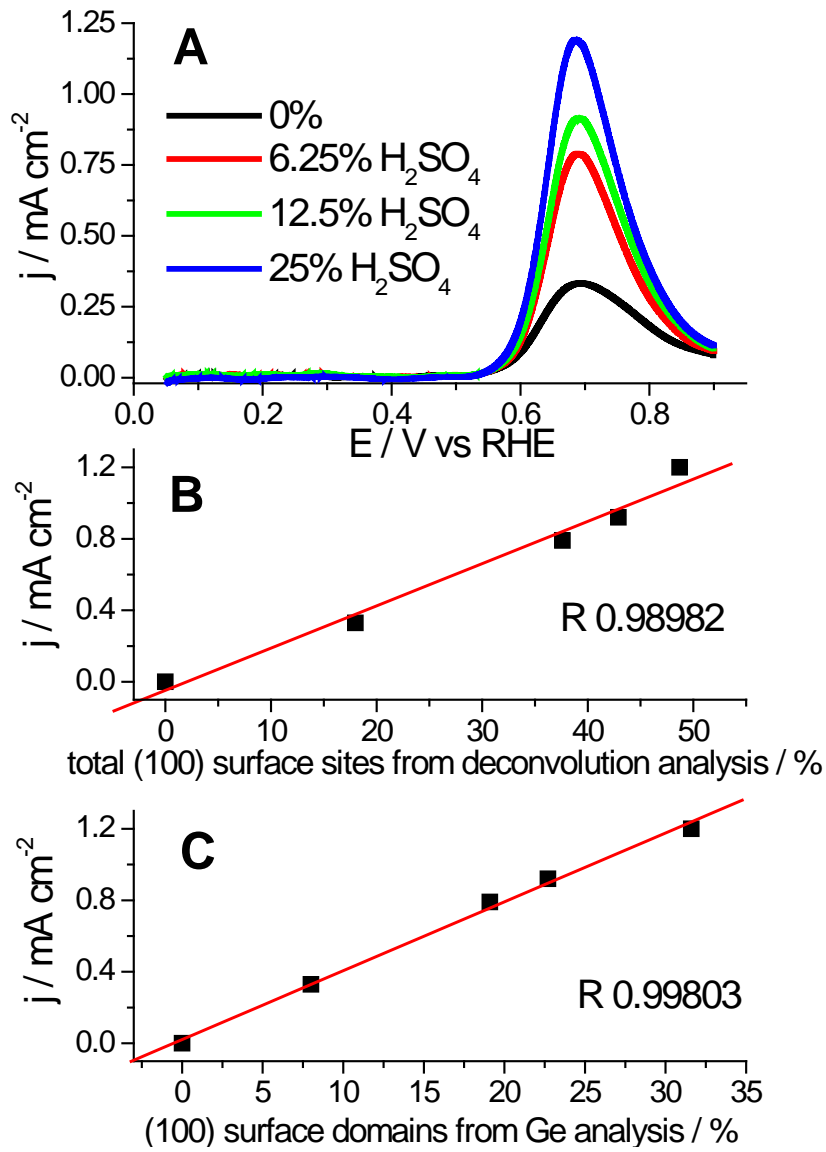

Figure 4. (A) Voltammetric profiles for ammonia oxidation with platinum nanoparticles prepared by water-in-oil microemulsion in the absence and presence of different amounts of $\mathrm{H} 2 \mathrm{SO} 4$. Test solution: $0.2 \mathrm{M} \mathrm{NaOH}+0.1 \mathrm{M}$ $\mathrm{NH}_{3}$. Scan rate: $10 \mathrm{mVs}^{-1}$. Linear fitting between the peak current density and (B) total amount of (100) surface sites and (C) amount of (100) surface domains.

Irreversible CO monolayer oxidation, also called CO stripping, is one of the most studied reactions in Electrocatalysis, not only because $\mathrm{CO}$ is a common poisoning intermediate in most of the $\mathrm{C} 1$ and $\mathrm{C} 2$ molecule organic oxidations, but also because it has been widely used as a surface probe molecule in fundamental studies. ${ }^{[11-34]} \mathrm{CO}$ monolayer oxidation is also known to be structure sensitive on Pt surfaces but with a minor structural sensitivity than ammonia electro-oxidation. ${ }^{[22,34,35]}$ In fact, in case of Pt nanoparticles, all surface sites contribute to the reaction although the $\mathrm{CO}$ oxidation peak coming from the (100) terraces is relatively wellseparated from the others and appears at a higher potential value. ${ }^{[11,36,37]}$ Figure 5 shows the CO stripping voltammograms obtained with the different Pt nanoparticles. The response of the polyoriented Pt nanoparticles, black line, shows a single and broad oxidation peak centred at $0.72 \mathrm{~V}$, while those prepared in the presence of $\mathrm{H}_{2} \mathrm{SO}_{4}$ show two different peaks located at 0.70 and $0.75 \mathrm{~V}$. From previous contributions with 


\section{COMIMUNICATIONS}

shaped Pt nanoparticles, it was established that the second of these two peaks is ascribed to the presence of (100) surface

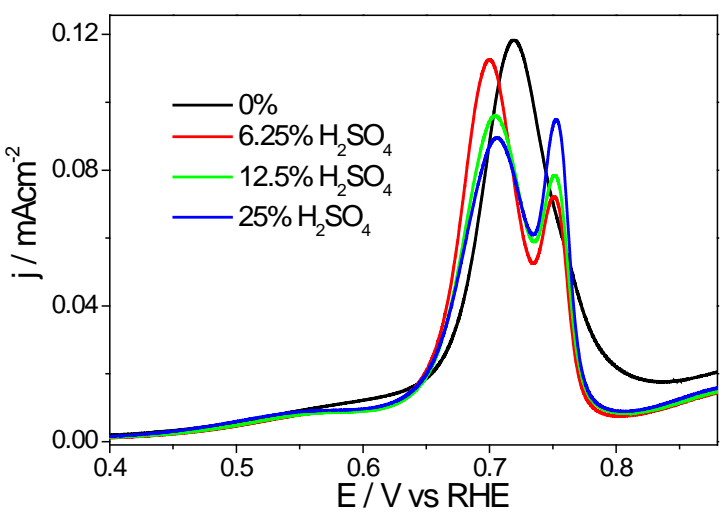

domains. ${ }^{[11,37]}$ Thus, as figure 5 shows, the increasing amount of (100) surface domains sites with the amount of $\mathrm{H}_{2} \mathrm{SO}_{4}$ results in a clear intensification of this second contribution in relation to the first one.

Figure 5. CO monolayer voltammograms obtained with platinum nanoparticles prepared in water-in-oil microemulsion in the absence and presence of different amounts of $\mathrm{H}_{2} \mathrm{SO}_{4}$. Test solution: $0.5 \mathrm{M} \mathrm{H}_{2} \mathrm{SO}_{4}$. Scan rate: $20 \mathrm{mVs}^{-1}$

In conclusion, this communication shows a simple, fast, economical and scalable route for the synthesis of $\mathrm{Pt}$ nanoparticles with a preferential (100) surface structure and a particle size about $9 \mathrm{~nm}$. The methodology is based on the chemical reduction of a platinum precursor by $\mathrm{NaBH}_{4}$ in a water-in-oil microemulsion in the presence of $\mathrm{H}_{2} \mathrm{SO}_{4}$ in the water phase of the microemulsion. It has been found that the (100) character of the samples increases with the amount of $\mathrm{H}_{2} \mathrm{SO}_{4}$. The maximum amount of $\mathrm{H}_{2} \mathrm{SO}_{4}$ that can be used without altering the stability of the microemulsion is $25 \%$. The resulting Pt nanoparticles approximately contain a $50 \%$ of (100) surface sites, $35 \%$ of which are wide surface domains with width $\geq 4 \mathrm{Pt}$ atoms. The preferential surface structure of the different nanoparticles has been electrochemically characterized by means of some structure sensitive reactions such as hydrogen and anion adsorption/desorption process and $\mathrm{Ge}$ adsoption desorption. Finally, the electrocatalytic properties of the samples have been evaluated towards ammonia and carbon monoxide electro-oxidations.

\section{Experimental Section}

Pt nanoparticles were synthesized by reducing $\mathrm{H}_{2} \mathrm{PtCl}_{6}$ with sodium borohydride $\left(\mathrm{NaBH}_{4}\right)$ using a water-in-oil (w/o) microemulsion of water $(3 \%) /$ polyethylene glycol dodecyl ether $(B R I J \circledast 30) \quad(16.5 \%) / n$-heptane $(80.5 \%)$ as previously reported. ${ }^{[19]}$ Values in brackets represent the volume percentage of each compound. The concentration of the $\mathrm{H}_{2} \mathrm{PtCl}_{6}$ solutions was always $0.1 \mathrm{M}$ although, to evaluate the effect of the presence of $\mathrm{H}_{2} \mathrm{SO}_{4}$, these were prepared using aqueous solutions containing a certain percentage of this acid.
The percentages studied were $0 \%$ (absence of $\mathrm{H}_{2} \mathrm{SO}_{4}$ ), $6.25 \%$, $12.5 \%$ and $25 \% \mathrm{H}_{2} \mathrm{SO}_{4}$ ). For higher concentrations of the acid, the microemulsion system became unstable. The reduction of platinum was achieved by adding solid $\mathrm{NaBH}_{4}$ to the water-inoil microemulsion solution. The amount of $\mathrm{NaBH}_{4}$ added was that to have a $1 \mathrm{M}$ concentration solution in the water phase $\left(\mathrm{NaBH}_{4} / \mathrm{Pt}\right.$ molar ratio of 10$)$. After complete reduction, which takes place in few minutes, acetone was added to the solution to cause phase separation. Afterwards, the Pt nanoparticles were cleaned with successive acetone, acetone-water mixtures and water washes to finally achieve a water suspension with clean nanoparticles. Finally the nanoparticles were stored in ultrapure water as a suspension.

The electrochemical experiments were performed in a threeelectrode electrochemical cell using a VMP3 multichannel potentiostat (BioLogic) working with a NStat configuration (1 counter electrode, 1 reference electrode and $\mathrm{N}$ working electrodes working simultaneously). The counter electrode was a platinum wire. Potentials were measured against a reversible hydrogen electrode (RHE) connected to the cell through a Luggin capillary. Before each experiment, the gold collector electrodes used to deposit the Pt NPs over were mechanically polished with alumina and rinsed with ultra-pure water to eliminate NPs from previous experiments. The active surface area of the Pt NPs was determined by the charge involved in the so-called hydrogen UPD region (between $0.06 \mathrm{~V}$ and 0.6 $\mathrm{V})$ after the subtraction of the double layer charging contribution and assuming the calibration ratio (UPD charge $) /\left(\right.$ Pt surface area) as $0.23 \mathrm{mC} \mathrm{cm}^{-2}$. ${ }^{38]}$

\section{Acknowledgements}

This work has been financially supported by the MCINNFEDER (Spain) (project CTQ 2010-16271), Generalitat Valenciana (project PROMETEO/2009/045) and in part by NASA-URC Grant No. NNX10AQ17A and NSF-NSEC Center for Hierarchical Manufactur-ing Grant No. CHM-CMMI0531171. R. $M-R$ is grateful to the Becas Iberoamérica, Santander Universidades-España 2012 and PR-LSAMP Bridge to Doctorate Fellowship programs.

\section{Keywords: ammonia • electrocatalysis • nanoparticles • platinum • shape}

[1] J. Solla-Gullon, F. J. Vidal-Iglesias, J. M. Feliu Annu. Rep. Prog Chem., Sect. C. 2011, 107, 263-297.

[2] C. Burda, X. Chen, R. Narayanan, M. A. El-Sayed Chem. Rev. 2005, 105, 1025-1102.

[3] Y. Xia, Y. Xiong, B. Lim, S. E. Skrabalak Angew. Chem. Int. Edit. 2009, 48, 60-103.

[4] A. R. Tao, S. Habas, P. Yang Small. 2008, 4, 310-325.

[5] M. T. M. Koper Nanoscale. 2011, 3, 2054-2073.

[6] R. A. Martínez-Rodríguez, F. J. Vidal-Iglesias, J. Solla-Gullon, C. R. Cabrera, J. M. Feliu J. Am. Chem. Soc. 2014.

[7] J. Solla-Gullón, P. Rodríguez, E. Herrero, A. Aldaz, J. M. Feliu Phys. Chem. Chem. Phys. 2008, 10, 1359-1373.

[8] F. J. Vidal-Iglesias, J. Solla-Gullón, P. Rodríguez, E. Herrero, V. Montiel, J. M. Feliu, A. Aldaz Electrochem. Commun. 2004, 6, 1080-1084.

[9] F. J. Vidal-Iglesias, R. M. Aran-Ais, J. Solla-Gullon, E. Herrero, J. M. Feliu ACS Catal. 2012, 2, 901-910. 
C. M. Sanchez-Sanchez, J. Solla-Gullon, F. J. Vidal-Iglesias, A. Aldaz, V. Montiel, E. Herrero J. Am. Chem. Soc. 2010, 132, 5622-5624.

[11] P. Urchaga, S. Baranton, C. Coutanceau, G. Jerkiewicz Langmuir. 2012, 28, 3658-3663.

[12] P. Urchaga, S. Baranton, T. W. Napporn, C. Coutanceau Electrocatalysis. 2010, 1-4.

[13] C. Coutanceau, P. Urchaga, S. Brimaud, S. Baranton Electrocatalysis. 2012, 3, 75-87.

[14] J. Monzó, M. T. M. Koper, P. Rodriguez ChemPhysChem. 2012 13, 709-715

[15] H. Yang, Y. Tang, S. Zou Electrochem. Commun. 2014, 38, 134137.

[16] Z.-Y. Zhou, N. Tian, Z.-Z. Huang, D.-J. Chen, S.-G. Sun Faraday Discuss. 2009, 140, 81-92.

[17] N. Tian, Z. Y. Zhou, S. G. Sun J. Phys. Chem. C. 2008, 112 19801-19817.

[18] A. A. Proussevitch, D. L. Sahagian Computers \& Geosciences. 2001, 27, 441-454

[19] J. Solla-Gullón, F. J. Vidal-Iglesias, A. López-Cudero, E. Garnier, J. M. Feliu, A. Aldaz Phys. Chem. Chem. Phys. 2008, 10, 36893698.

[20] A. Kuzume, E. Herrero, J. M. Feliu J. Electroanal. Chem. 2007. 599, 333-343.

[21] N. P. Lebedeva, A. Rodes, J. M. Feliu, M. T. M. Koper, R. A. van Santen J. Phys. Chem. B. 2002, 106, 9863-9872.

[22] N. P. Lebedeva, M. T. M. Koper, E. Herrero, J. M. Feliu, R. A. van Santen J. Electroanal. Chem. 2000, 487, 37-44.

[23] F. J. Vidal-Iglesias, J. Solla-Gullón, V. Montiel, J. M. Feliu, A. Aldaz J. Phys. Chem. B. 2005, 109, 12914-12919.

[24] P. Rodríguez, E. Herrero, J. Solla-Gullón, E. J. Vidal-Iglesias, A. Aldaz, J. M. Feliu Electrochim. Acta. 2005, 50, 3111-3121.

[25] P. Rodríguez, E. Herrero, J. Solla-Gullón, F. J. Vidal-Iglesias, A Aldaz, J. M. Feliu Electrochim. Acta. 2005, 50, 4308-4317. F. J. Vidal-Iglesias, N. Garcia-Araez, V. Montiel, J. M. Feliu, A.
E. Bertin, S. Garbarino, D. Guay, J. Solla-Gullón, F. J. VidalIglesias, J. M. Feliu J. Power Sources. 2013, 225, 323-329.

[28] S. Le Vot, L. Roué, D. Bélanger J. Electroanal. Chem. 2013, 691, 18-27.

[29] V. Rosca, M. Duca, M. T. de Groot, M. T. M. Koper Chem. Rev. 2009, 109, 2209-2244.

[30] J. Solla-Gullón, F. J. Vidal-Iglesias, P. Rodríguez, E. Herrero, J. M. Feliu, J. Clavilier, A. Aldaz J. Phys. Chem. B. 2004, 108, 13573-13575.

[31] F. Maillard, E. R. Savinova, U. Stimming J. Electroanal. Chem. 2007, 599, 221-232.

A. Wieckowski, E. R. Savinova, C. G. Vayenas, Catalysis and electrocatalysis at nanoparticle surfaces, CRC Press, New York, 2003.

N. M. Markovic, P. N. Ross Surf. Sci. Rep. 2002, 45, 117-229.

M. T. M. Koper, S. C. S. Lai, E. Herrero in Mechanisms of the Oxidation of Carbon Monoxide and Small Organic Molecules at Metal Electrodes, Vol. (Ed. M. T. M. Koper), John Wiley \& Sons, Inc, Hoboken, NJ, 2009, pp.159208.

[35] F. J. Vidal-Iglesias, J. Solla-Gullón, J. M. Campina, E. Herrero, A. Aldaz, J. M. Feliu Electrochim. Acta. 2009, 54, 4459-4466.

[36] S. Brimaud, S. Pronier, C. Coutanceau, J. M. Léger Electrochem. Commun. 2008, 10, 1703-1707.

[37] J. Solla-Gullón, F. J. Vidal-Iglesias, E. Herrero, J. M. Feliu, A. Aldaz Electrochem. Commun. 2006, 8, 189-194.

[38] Q. S. Chen, J. Solla-Gullon, S. G. Sun, J. M. Feliu Electrochim. Acta. 2010, 55, 7982-7994.

Received: ((will be filled in by the editorial staff))

Published online: ((will be filled in by the editorial staff)) Aldaz Electrochem. Commun. 2003, 5, 22-26. 


\section{Entry for the Table of Contents}

\section{COMMUNICATION}

\section{Easy shape control of}

nanoparticles: Sulphuric acid is used as surface modifier to synthesise (100) Pt nanoparticles using a waterin-oil microemulsion method. The electrocatalytic properties of the resulting cubic-like Pt nanoparticles are evaluated towards ammonia and CO electro-oxidations.

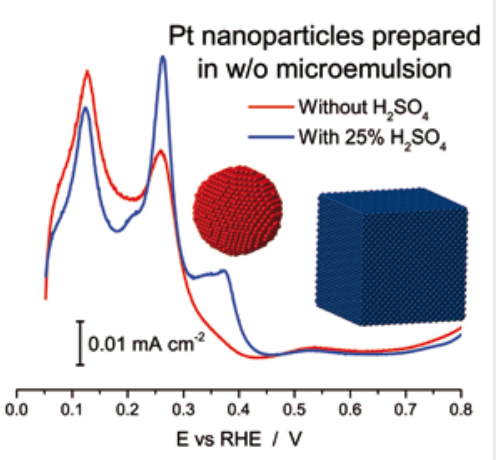

Roberto A. Martínez-Rodríguez,

Francisco J. Vidal-Iglesias, José SollaGullón, Carlos R. Cabrera, and Juan M. Feliu*

Page No. - Page No.

Synthesis and electrocatalytic properties of $\mathrm{H}_{2} \mathrm{SO}_{4}$-induced (100) Pt nanoparticles prepared in water-in-oil microemulsion 